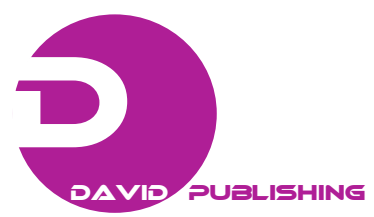

\title{
Potential Applications of HS-SPME/GC in Oxidized Vegetable Oils
}

\author{
Gülgün Yildiz Tiryaki \\ Department of Food Engineering, Faculty of Agriculture, Kahramanmaras Sutcu Imam University, Kahramanmaras 46100, Turkey
}

Received: February 4, 2012 / Published: May 20, 2012.

\begin{abstract}
Headspace solid phase microextraction chromatography (HS-SPME/GC) was evaluated as a tool in determining the rate of oxidation in oxidized soybean oil samples by measuring the production of hexanal as a secondary major volatile breakdown product of linoleic acid. Samples of the headspace taken from sealed $20 \mathrm{~mL}$ vials, incubated $30 \mathrm{~min}$ at $50{ }^{\circ} \mathrm{C}$ followed by $5 \mathrm{~min}$ adsorption, were injected into a gas chromatograph with 2 min thermal desorption. In applying SPME, different analytical conditions were evaluated. The linearity of response of the volatiles for the HS-SPME/GC procedure using a carboxen-polydimethylsiloxane fiber was determined from $3 \mathrm{~g}$ of mineral oil spiked with a hexanal standard solution at different levels. Using the optimized extraction conditions, an $R$ value close to unity $(R=0.999)$ was found, and the repeatability $(\mathrm{n}=11)$ was $6.31 \%$. The results indicated that hexanal is linearly related to peroxide value (PV) only intermediate PV ranges $(10-18 \mathrm{meq} / \mathrm{kg})$. The study also showed that HS-SPME/GC procedure was a simple and reproducible method for the analysis of hexanal in the HS of commercial soybean oil samples, and is useful as a quality control and research tool for the evaluation of flavor quality and shelf life of vegetable oils.
\end{abstract}

Key words: Hexanal, headspace, GC, solid phase microextraction, peroxide value, oxidation, vegetable oil.

\section{Introduction}

Degradation of lipids results in the formation of volatile compounds that affect the flavor and safety of food products. Oxidation of unsaturated lipids results in the formation of hydroperoxides, which are tasteless and odorless [1]. Undesirable flavors and odors associated with rancidity of oxidized lipids arise from decomposition of these hydroperoxides. Lipid oxidation usually results in increases in peroxide value, hyroperoxide concentration and volatile content [2, 3].

Various techniques have been reported for gas chromatography volatile analysis in oils and oil-based foods, ranging from direct injection to various purge-trap systems [4]. Headspace gas chromatography (HS-GC) analysis is a simple technique that measures volatile compounds

Corresponding author: Gülgün Yildiz Tiryaki, assistant professor, research fields: the development of rapid analytical methods for measuring food quality. E-mail: gtiryaki@ksu.edu.tr. equilibrated with liquid or solid samples in a closed system $[5,6]$. This method has been used to analyze hexanal as a lipid peroxidation product in cereal foods [7, 8]. Capillary GC has provided a significant improvement in methodology to investigate volatile decomposition products in oxidized vegetable oils. Determination of volatile components in a mixture is a process widely used in many disciplines, such as environmental, food, forensic, oil, pharmaceutical, and polymer analysis [9-23]. Synder et al. [9] compared techniques for volatile analyses of soybean oil (SBO) including direct injection, static headspace and dynamic headspace.

A wide variety of analytical techniques for sample preparation, such as vacuum distillation, HS analysis, and supercritical fluid extraction have been developed to determine the concentration of volatile flavor components in foods.

The use of toxic organic solvents in sample preparation for volatile analysis has caused concerns 
among regulatory agencies. Ideally, sample preparation should be solvent free, simple, inexpensive, efficient, selective, and compatible with various analytical instruments [24-26]. Solvent free extractions are categorized into three areas, namely gas phase, membrane extractions, and sorbent extractions. The gas phase includes static HS, dynamic HS (e.g., purge and trap) and supercritical fluid extraction. The drawbacks to these methods include, but are not limited to, low sensitivity and cross-contamination [27].

The solid phase microextraction (SPME) technique eliminates most of these drawbacks. Sorbent extraction, however, of which solid phase extraction is the most commonly used, is simple, inexpensive, usable in the field, can be automated and uses little or no solvent. The cylindrical geometry provided by a microextraction method, called SPME, results in increased mass transfer during extraction and desorption, preventing the problem of plugging, and can readily be interfaced with analytical instruments [28].

SPME contains a fused silica fiber with an outer coating of polymeric organic liquid or solid [29, 30]. In HS analysis the coated fiber is inserted into the vapor phase above the sample. Volatilized components adsorb to the polymeric material and are extracted from the headspace. During the analysis of headspace by SPME, two equilibria should be reached by the analytes: between the matrix and the headspace and between the headspace and the coating of the fiber [27]. The theoretical aspects of HS-SPME for a three-phase system have been described in detail and generalized for a multiphase situation [28, 31].

Compare to other GC methods used for volatile analyses in foods and lipid systems, SPME is a low cost, rapid, sensitive, solventless and portable sample preparation technique. Thus, it has been applied in a variety of analytical applications since first being described by Belardi and Pawliszyn [32-49].

In the present study, HS-SPME/GC was evaluated as a tool for determining the rate of oxidation by measuring the production of hexanal as a secondary breakdown product in oxidized SBO samples. In applying SPME different analytical conditions were evaluated. This paper describes a rapid HS-SPME/GC method to determine hexanal, a major volatile decomposition product of linoleic acid produced by SBO samples.

\section{Materials and Methods}

\subsection{Selection of Soybean Oil Samples}

Three SBO samples representing two commercial brands with different "sell by" dates and batch codes were purchased from local supermarkets.

\subsection{Oxidation of Soybean Oils}

Samples $(100 \mathrm{~g})$ of non-stripped SBO were weighed into $110 \mathrm{~mL}$ glass jars. Different levels of oxidation were generated in the samples by using an oven method at $60{ }^{\circ} \mathrm{C}$, and each bottle was separately subjected to the oxidation, to establish replication. Samples for chemical and HS-SPME/GC analyses were taken every day, and peroxide value (PV) determinations using the standard peroxide value method (AOCS Method Cd 8-53) [50] were continued until PV of $20 \mathrm{meq} / \mathrm{kg}$ was reached for each treatment. A total of 17 oil samples were analyzed. For PV analysis, the oil samples were removed sequentially and were returned immediately to the same position in the oven after sampling. PV determinations were done in duplicate. The entire sampling and peroxide determination was completed in less than $30 \mathrm{~min}$. After PV measurement, samples ( $3 \mathrm{~g}$ ) of each oil were placed into HS sample vials, and kept in a freezer $\left(-20^{\circ} \mathrm{C}\right)$ until used for HS-SPME/GC analysis.

\subsection{Standard}

To check the linearity of calibration, a hexanal standard was obtained from the Aldrich Chemical Co. (Milwaukee, WI). Prior to use a standard for HS-SPME/GC analyses, the hexanal was purified by passing a sample of about $0.5 \mathrm{~mL}$ trough a Waters 
Sep-Pak silica cartridge (Waters Associates, Milford, MA) immediately prior to use [51], and then sealing it in a $20 \mathrm{~mL}$ vial under nitrogen. Accurate dilutions for the volatile standard solutions were prepared using mineral oil. A hexanal standard curve was developed using concentrations of $0.1,1$ and $10 \mathrm{ppm}$. These solutions were prepared from a stock solution (100 ppm) of standard hexanal in mineral oil which was prepared daily.

\subsection{SPME Analysis}

\subsubsection{HS-SPME Equipment and Procedure}

The SPME device consisting of a manual holder and reusable fused silica fiber assembly were obtained from Supelco Co. (Bellefonte, PA). The fused silica fiber coated with carboxen/polydimethylsiloxane (Car-PDMS) (75 $\mu \mathrm{m}$ film thickness) was studied. For HS-SPME of lipid materials, $20 \mathrm{~mL}$ crimp-top HS vials, with PTFE/BYTL septa, and $20 \mathrm{~mm}$ crimp cap aluminum seals (Agilent, USA/Germany) were used. Care was taken to clean the vials before use. For preparing a standard curve, $3 \mathrm{~g}$ samples of appropriate standard solutions in mineral oil were accurately weighed into tared HS vials and immediately sealed. Similarly, $3 \mathrm{~g}$ samples of vegetable oil were accurately weighed into tared HS vials and immediately sealed.

\subsubsection{Sample Adsorption}

Prior to sampling the HS, tightly closed vials containing the standards in mineral oil and SBO samples were placed and maintained in a heated $\left(50{ }^{\circ} \mathrm{C}\right)$ block $[26,34]$ for $30 \mathrm{~min}$ to allow for headspace equilibration. SPME was then performed with a Car-PDMS $75 \mu \mathrm{m}$ fiber. A sampling time from the HS of the vial of exactly 5 min was chosen. To do that the fiber assembly needle was inserted through the septum of each vial, and the fiber assembly needle was inserted through the septum of each vial, and the fiber exposed to the sample HS for $5 \mathrm{~min}$. The objective was to reach equilibrium of the analytes between the fiber coating and HS.
2.4.3 SPME Desorption, Chromatography and Detection

After the HS-SPME adsorption step was completed, the fiber was then retracted into the syringe, the fiber assembly needle withdrawn from the septum, and the adsorbed substances from the SPME fiber immediately analyzed. The needle was introduced into the heated injection port of the GC to about the midpoint of the heated zone, and the injector and column oven programs initiated. Rapid and total desorption of the adsorbed substances from the SPME fiber is essential for quantification purposes. Therefore, immediately after initiation of the program, the fiber was exposed to the high temperature of the injection port in order to thermally desorb the analytes onto the column for analysis. The fiber was left in place for the required time ( $2 \mathrm{~min}$ ) and the integrated peak areas obtained. The 2 min desorption time was based on literature [27] where Arthur and Pawlizyn [27] recommended sampling. Peak identification was made by using known volatile standards. Volatile compounds in SBO samples were separated, and by comparing their GC retention times with that of standard compound (hexanal), individual sample volatile peaks were identified. The GC peak areas and retention times were measured and recorded with a Hewlett Packard Model HP 6890 Integrator (Avondale, PA).

\subsection{GC Conditions}

A Hewlett Packard Gas Chromatograph (Model HP 6890; Avondale, PA) was used for SPME desorption, analyte separation and detection. The gas chromatograph was equipped with a flame ionization detector. The injection port was maintained at $230{ }^{\circ} \mathrm{C}$ and the detector at $250{ }^{\circ} \mathrm{C}$. The analytes were separated with a DB-1701 column (15 m; $0.32 \mathrm{~mm}$ id; $1 \mu \mathrm{m}$ film thickness; J\&W Scientific, Folsom, CA). The column oven was programmed from $40^{\circ} \mathrm{C}(2 \mathrm{~min}$ hold) to $80{ }^{\circ} \mathrm{C}$ at $10{ }^{\circ} \mathrm{C} \mathrm{min}^{-1}$ followed by a 4 min hold. Helium was used as carrier gas at flow rate 1.5 
$\mathrm{mL} / \mathrm{min}$ with a splitless injection mode and $2 \mathrm{~min}$ purge time. A short "bake-out" program was run to purge the system and removed any carryover material between runs.

\section{Results and Discussion}

HS-SPME/GC was evaluated as a tool for determining the rate of oxidation in oxidized SBO samples by measuring the production of hexanal as a secondary breakdown product of linoleic acid. In applying solid phase microextraction, different analytical conditions were evaluated.

The volatile compounds, generated from oxidized SBO $(\mathrm{n}=17)$, were collected by a SPME static HS sampling method. These were analyzed by a capillary gas chromatograph with a flame ionization detector. Initial work was done to establish GC conditions and absorption/desorption times for the fiber, in order to obtain adequate resolution and maximum peak areas for the compounds of interest. Investigated GC parameters were the carrier gas flow rate (from 1.5 $\mathrm{mL}$ to $3 \mathrm{~mL} / \mathrm{min}$ ), purge time (1 $\mathrm{min}$ to $3 \mathrm{~min}$ ), initial oven temperature (from $30^{\circ} \mathrm{C}$ to $40^{\circ} \mathrm{C}$ ), and oven rate (from $5{ }^{\circ} \mathrm{C} \min ^{-1}$ to $10{ }^{\circ} \mathrm{C} \min ^{-1}$ ). HS sampling techniques were also investigated for heating time to reach equilibrium, and adsorption time (5 $\mathrm{min}$ ) and desorption time ( $2 \mathrm{~min}$ ) for the fiber.

Different analytical conditions were evaluated. Samples of the headspace were taken from $20 \mathrm{~mL}$ vials incubated $30 \mathrm{~min}$ at $50{ }^{\circ} \mathrm{C}$ using a carboxen-polydimethysiloxane (Car-PDMS) fiber and 5 min adsorption time. Volatiles were then desorbed into a GC using a 2 min thermal desorption. The study showed that SPME/HS-GC was a simple method for hexanal determination, and satisfactory repeatability was obtained by the method $(n=11, \mathrm{CV} \%=6.31)$.

A manually operated SPME holder and reusable fused silica fiber ( $75 \mu \mathrm{m}$ film thickness) coated with Car-PDMS (Supelco Co., Bellefonte, PA) were used throughout the study. Page and Lacroix [52] stated that the HS-SPME efficiencies of the recently available Car-PDMS and divinylbenzene-Carboxen-PDMS (DVB-Car-PDMS) fibers were found to be much greater than those of the PDMS fibre for a number of volatile contaminants in vegetable oil lipids.

\subsection{Extraction Temperature and Times}

In this study, a sampling temperature of $50{ }^{\circ} \mathrm{C}$ was chosen and applied based on the literature [26, 34]. The effect of different extraction times on the analyte response from $3 \mathrm{~g}$ of vegetable oil using the Car-PDMS fiber was studied at $50{ }^{\circ} \mathrm{C}$ for periods from $10 \mathrm{~min}$ to $50 \mathrm{~min}$. The sample equilibration time represents the time needed for saturation of the fiber coating. Equilibration was usually reached within 30 min (Fig. 1) and a HS-SPME temperature of $50{ }^{\circ} \mathrm{C}$ with time of 30 min was used for the remainder of the study.

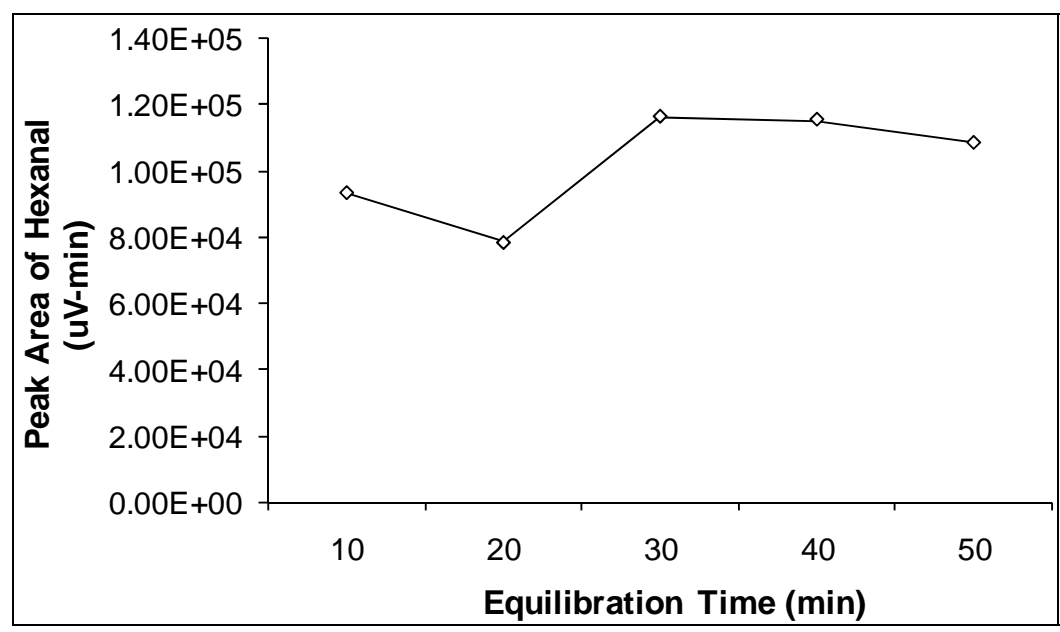

Fig. 1 Effect of sampling time on peak area of hexanal volatile fraction in mineral oil. 


\subsection{Studies with Oxidized Vegetable Oil}

The HS-SPME/GC method was used to analyze volatiles in an attempt to draw a relationship between volatile (hexanal) profile and PV. With the experimental conditions, measurements of the oxidized SBO were made. Peak identification was made by using known volatile standard (hexanal). Hexanal was identified in the gas chromatograms of HS from oxidized SBO samples with a retention time ranging between 7.196 and $7.211 \mathrm{~min}$, and the amount of hexanal was determined by GC peak area from each chromatogram. Fig. 2 represents typical chromatogram of an oxidized SBO $(\mathrm{PV}=4.9 \mathrm{meq} / \mathrm{kg})$. Comparison of PV data and HS-SPME/GC hexanal data from the SBO oxidation is shown in Fig. 3. The headspace hexanal content increased rapidly as PV increased from 0-5 meq $/ \mathrm{kg}$, but the headspace hexanal

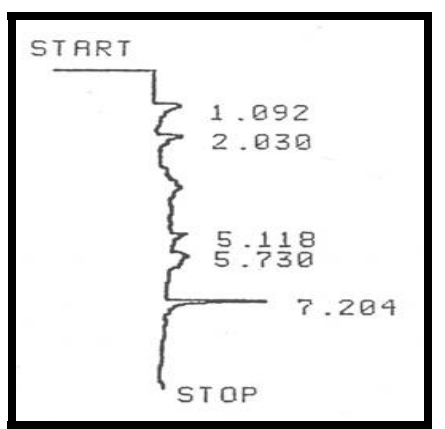

Fig. 2 GC chromatogram of volatiles from an oxidized SBO by SPME-sampled HS.

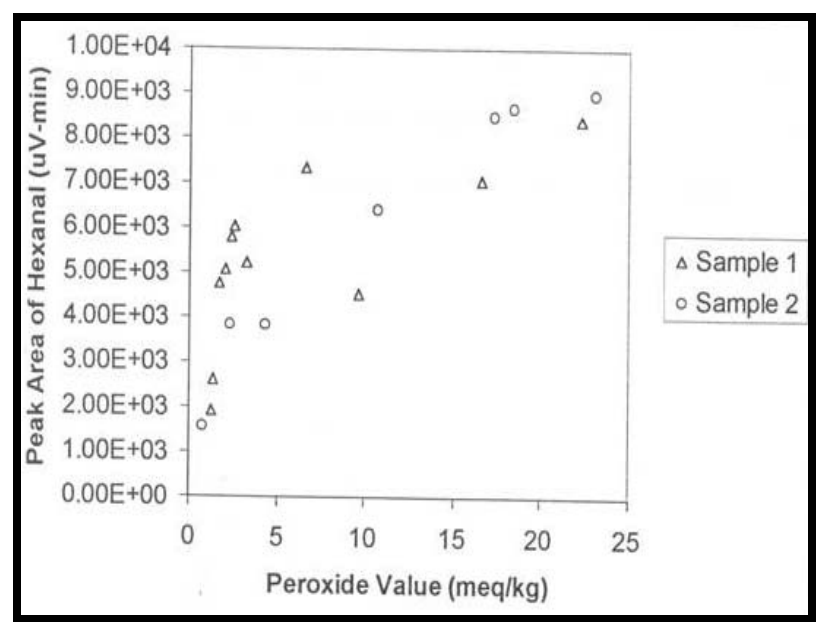

Fig. 3 Scatter plot of data for the official AOCS PV method Cd 8-53 vs. the our optimized HS-SPME/GC method for hexanal in the oxidized SBO samples. content increased more slowly over the PV range from $5-20 \mathrm{meq} / \mathrm{kg}$. In sample 1 , one data point $(\mathrm{PV}=10$ $\mathrm{meq} / \mathrm{kg}$ ) appears to be an outlier, but the reason for this is not clear.

Steenson et al. [53] also used Car-PDMS, carbowax/divinylbenzene, and polyacrylate fibers, and they stated that the Car-PDMS fiber was found to have the best overall combination of sensitivity, reproducibility, and durability for analysis of compounds in the HS of SBO.

Moreover, Mateus et al. [54] preferred the similar fibre coated with $75 \mathrm{~mL}$ CAR/PDMS film (same thickness) in their study for the extraction, identification, and quantification of ethanol, as well. The limits of quantification were registered at levels of parts per million. Quantification of ethanol was successfully performed in fish stew and beef bib by external standard method [54].

\section{Conclusions}

Based on the research presented, the following conclusions were made: compared to other GC methods used for volatile analyses in foods and lipid systems, the HS-SPME/GC method is a simple, rapid and reproducible method for the analysis of volatile compounds in the headspace of commercial SBO's, and hexanal is linearly related to PV only intermediate PV ranges (10-18 meq/kg). Therefore, this method can be used as a quality control and research tool for the evaluation of flavor quality, screening for oxidation of vegetable oils.

Other advantages of the method are that it does not require special sample preparation. The solvent-free solid phase microextraction may be useful in determining the shelf life of soybean oils more rapidly and conveniently than current methods.

Further investigation should be performed to evaluate the applicability of the solid phase microextraction procedure on a variety of lipid samples, including different edible vegetable oils and their mixtures. 


\section{References}

[1] E.N. Frankel, Volatile lipid oxidation products, Prog. Lipid Res. 22 (1982) 1-33.

[2] K. Warner, C.D. Evans, G.R. List, H.P. Dupuy, J.I. Wadsworth, D.E. Goheen, Flavor score correlation with pentanal and hexanal contents of vegetable oils, J. Am. Oil Chem. Soc. 55 (1978) 252-256.

[3] G. Yıldız Tiryaki, Methodology for measuring peroxide value in vegetable oils, Ph.D. Thesis, University of Nebraska, Lincoln, Nebraska-USA, 2001, p. 101.

[4] T.H. Applewhite, Bailey's Industrial Oil and Fat Products, Vol. 3, John Wiley and Sons, Inc., New York, 1985, p. 243.

[5] H. Hachhenberg, A.P. Schmidt, Gas Chromatographic Headspace Analysis, Heyden and Son Ltd., London, 1977.

[6] B. Loffe, A.G. Vitenberg, Headspace Analysis and Related Methods, John Wiley and Sons, New York, 1984.

[7] C.W. Fritsch, J.A. Gale, Hexanal as a measure of rancidity in low fat foods, J. Am. Oil. Chem. Soc. 54 (1977) 225-228.

[8] E.N. Frankel, A.M. Nash, J.M. Snyder, A methodology study to evaluate quality of soybeans stored at different moisture levels, J. Am. Oil Chem. Soc. 64 (1987) 987-992.

[9] J.M. Synder, E.N. Frankel, E. Selke, K. Warner, Comparison of gas chromatographic methods for volatile lipid oxidation compounds in soybean oil, J. Am. Oil Chem. Soc. 65 (1988) 1617-1620.

[10] M. De Fátima Alpendurada, Solid-phase microextraction: A promising technique for sample preparation in environmental analysis, J. Chromatogr. A 889 (1-2) (2000) 3-14.

[11] J.C. Flórez Menéndez, M.L. Fernández Sánchez, E. Fernández Martinez, J.E. Sánchez Uría, A. Sanz-Medel, Static headspace versus head space solid-phase microextraction (HS-SPME) for the determination of volatile organochlorine compounds in landfill leachates by gas chromatography, Talanta 63 (4) (2004) 809-814.

[12] C. Dong, Z. Zeng, M. Yang, Determination of organochlorine pesticides and their derivations in water after HS-SPME using polymethylphenylvinylsiloxane-coated fiber by GC-ECD, Water Res. 39 (17) (2005) 4204-4210.

[13] P. Poinot, J. Grua-Priol, G. Arvisenet, C. Rannou, M. Semenou, A. Le Bail, et al., Optimisation of HS-SPME to study representativeness of partially baked bread odorant extracts, Food Res. Int. 40 (9) (2007) 1170-1184.

[14] G. Pecoraino, L. Scalici, G. Avellone, L. Ceraulo, R. Favara, E.G. Candela, et al., Distribution of volatile organic compounds in Sicilian groundwaters analysed by head space-solid phase micro extraction coupled with gas chromatography mass spectrometry (SPME/GC/MS): Review article, Water Res. 42 (14) (2008) 3563-3577.

[15] S. Gabbanini, E. Lucchi, M. Carli, E. Berlini, A. Minghetti, L. Valgimigli, In vitro evaluation of the permeation through reconstructed human epidermis of essentials oils from cosmetic formulations, J. Pharm. Biomed. Anal. 50 (3) (2009) 370-376.

[16] M. Khoobchandani, B.K. Ojeswi, N. Ganesh, M.M. Srivastava, S. Gabbanini, R. Matera, et al., Antimicrobial properties and analytical profile of traditional eruca sativa seed oil: Comparison with various aerial and root plant extracts, Food Chem. 120 (1) (2010) 217-224.

[17] C. Tessini, N. Müller, C. Mardones, D. Meier, A. Berg, D. von Baer, Chromatographic approaches for determination of low-molecular mass aldehydes in bio-oil, J. Chromatogr. A 1219 (2012) 154-160.

[18] L. Ning, Z. Fu-ping, C. Hai-tao, L. Si-yuan, G. Chen, S. Zhen-yang, et al., Identification of volatile components in Chinese Sinkiang fermented camel milk using SAFE, SDE, and HS-SPME-GC/MS, Food Chem. 129 (3) (2011) $1242-1252$.

[19] B. Huang, Y. Lei, Y. Tang, J. Zhang, L. Qin, J. Liu, Comparison of HS-SPME with hydrodistillation and SFE for the analysis of the volatile compounds of Zisu and Baisu, two varietal species of Perilla frutescens of Chinese origin, Food Chem. 125 (1) (2011) 268-275.

[20] O. Lasekan, Headspace solid-phase microextraction gas chromatography-mass spectrometry (HS-SPME-GC-MS) determination of volatile compounds in roasted plantains (French sombre and Dwarf Kalapua), LWT-Food Sci.Technol. 46 (2) (2012) 536-541.

[21] S. Balme, F.O. Gülaçar, Rapid screening of phytosterols in orange juice by solid-phase microextraction on polyacrylate fibre derivatisation and gas chromatographic-mass spectrometric, Food Chem. 132 (1) (2012) 613-618.

[22] G. Sagratini, F. Maggi, G. Caprioli, G. Cristalli, M. Ricciutelli, E. Torregiani, et al., Comparative study of aroma profile and phenolic content of Montepulciano monovarietal red wines from the Marches and Abruzzo regions of Italy using HS-SPME-GC-MS and HPLC-MS, Food Chem. 132 (3) (2012) 1592-1599.

[23] Z. Ayhan, A. Döş, Gıdalarda katı faz mikroekstaksiyon tekniği ile flavor analizi, Gida 29 (2) (2004) 169-175.

[24] Z. Zhang, M.J. Yang, J. Pawliszyn, Solid-phase microextraction: A solvent-free alternative for sample preparation, Anal. Chem. 66 (1994) 844A-853A.

[25] X. Yang, T. Peppard, Solid-phase microextraction for flavor analysis, J. Agric. Food Chem. 42 (1994) 1925-1930.

[26] J.A. Field, G. Nickerson, D.D. James, C. Heider, 
Determination of essential oils in hops by headspace solid-phase microextraction, J. Agric. Food Chem. 44 (1996) 1768-1772.

[27] C.L. Arthur, J. Pawliszyn, Solid phase microextraction with thermal desorption using fused silica optical fibers, Anal. Chem. 62 (1990) 2145-2148.

[28] Z. Zhang, J. Pawliszyn, Headspace solid-phase microextraction, Anal. Chem. 65 (1993) 1843-1852.

[29] J. Pawliszyn, Solid Phase Microextraction-Theory and Practice, Wiley-VCH, New York, 1997, p. 275.

[30] Supelco, Solid phase microextraction troubleshooting guide, Bulletin 928, Bellefonte, PA, 2001.

[31] W. Wardencki, M. Michulec, J. Curyło, A review of theoretical and practical aspects of solid-phase microextraction in food analysis, Int. J. Food Sci. Technol. 39 (7) (2004) 703-717.

[32] R. Berlardi, J. Pawliszyn, The application of chemically modified fused silica fibers in the extraction of organics from water matrix samples and their rapid transfer to capillary columns, Water Pollution Res. J. Canada 23 (1989) 179.

[33] R. Giuffrida, M.T. Clasadonte, A. Zerbo, Determination of benzene and toluene in vegetable oils by SPME/HPLC, J. Commod. Sci. 38 (1999) 3-14.

[34] H.H. Jelen, M. Obuchowska, R. Zawirska-Wojtasiak, E. Wasowicz, Headspace solid-phase microextraction use for the characterization of volatile compounds in vegetable oils of different sensory quality, J. Agric. Food Chem. 48 (2000) 2360-2367.

[35] S. Mildner-Szkudlarz, H.H. Jeleń, R. Zawirska-Wojtasiak, E. Wasowicz, Application of headspace-Solid phase microextraction and multivariate analysis for plant oils differentiation, Food Chem. 83 (4) (2003) 515-522.

[36] F. Doleschall, K. Recseg, Z. Kemény, K. Kovári, Comparison of differently coated SPME fibres applied for monitoring volatile substances in vegetable oils, Int. J. Food Sci. Technol. 105 (7) (2003) 333-338.

[37] A. Cimato, D. Dello Monaco, C. Distante, M. Epifani, P. Siciliano, A.M. Taurino, et al., Analysis of single-cultivar extra virgin olive oils by means of an Electronic Nose and HS-SPME/GC/MS methods, Sens. Actuators, B: Chemical 114 (2) (2006) 674-680.

[38] M. Contini, M. Esti, Effect of the matrix volatile composition in the headspace solid-phase microextraction analysis of extra virgin olive oil, Food Chem. 94 (1) (2006) 143-150.

[39] J. Lee, D.H. Kim, P.S. Chang, J. Lee, Headspace-solid phase microextraction (HS-SPME) analysis of oxidized volatiles from free fatty acids (FFA) and application for measuring hydrogen donating antioxidant activity, Food Chem. 105 (1) (2007) 414-420.

[40] A. Barra, N. Baldovini, A.M. Loiseau, L. Albino, C.
Lesecq, L.L. Cuvelier, Chemical analysis of French beans (Phaseolus vulgaris L.) by headspace solid phase microextraction (HS-SPME) and simultaneous distillation/extraction (SDE), Food Chem. 101 (3) (2007) $1279-1284$

[41] J. Iglesias, S. Lois, I. Medina, Development of a solid-phase microextraction method for determination of volatile oxidation compounds in fish oil emulsions, J. Chromatogr. A 1163 (1-2) (2007) 277-287.

[42] H. Manai, F. Mahjoub-Haddada, I. Oueslati, D. Daoud, M. Zarrouk, Characterization of monovarietal virgin olive oils from six crossing varieties, Sci. Hort. 115 (3) (2008) 252-260.

[43] B. Rega, A. Guerard, J. Delarue, M. Maire, P. Giampaoli, On-line dynamic HS-SPME for monitoring endogenous aroma compounds released during the baking of a model cake, Food Chem. 112 (1) (2009) 9-17.

[44] F. Maggi, F. Papa, G. Cristalli, G. Sagratini, S. Vittori, Characterisation of the mushroom-like flavour of Melittis melissophyllum L. subsp. melissophyllum by headspace solid-phase microextraction (HS-SPME) coupled with gas chromatography (GC-FID) and gas chromatography-mass spectrometry (GC-MS), Food Chem. 123 (4) (2010) 983-992.

[45] A. Beltrán, M. Ramos, N. Grané, M.L. Martín, M.C. Garrigós, Monitoring the oxidation of almond oils by HS-SPME-GC-MS and ATR-FTIR: Application of volatile compounds determination to cultivar authenticity, Food Chem. 126 (2) (2011) 603-609.

[46] K.E. Pickl, V. Adamek, R. Gorges, F.M. Sinner, Headspace-SPME-GC/MS as a simple cleanup tool for sensitive 2,6-diisopropylphenol analysis from lipid emulsions and adaptable to other matrices, J. Pharm. Biomed. Anal. 55 (5) (2011) 1231-1236.

[47] C. Pizarro, S. Rodríguez-Tecedor, N. Pérez-del-Notario, J.M. González-Sáiz, Recognition of volatile compounds as markers in geographical discrimination of Spanish extra virgin olive oils by chemometric analysis of non-specific chromatography volatile profiles, J. Chromatogr. A 1218 (3) (2011) 518-523.

[48] J. Sun, B. Yu, P. Curran, S.Q. Liu, Quantitative analysis of volatiles in transesterified coconut oil by headspace-solid-phase microextraction-gas chromatography-mass spectrometry, Food Chem. 129 (4) (2011) 1882-1888.

[49] R.Q. Alvarez, C.C. Passaro, O.G. Lara, J.L. Londono, Relationship between chromatographic profiling by HS-PME and sensory quality of mandarin juices: Effect of squeeze technology, Procedia Food Sci. 1 (2011) 1396-1403.

[50] AOCS, Official Methods and Recommended Practices of the American Oil Chemists's Society, 4th ed., American 
Oil Chemists' Society, Champaign, 1990.

[51] E.N. Frankel, M.L. Hu, A.L. Tappel, Rapid headspace gas chromatography of hexanal as a measure of lipid peroxidation in biological samples, Lipids 24 (1989) 976-981.

[52] B.D. Page, G. Lacroix, Analysis of volatile contaminants in vegetable oils by headspace solid-phase microextraction with carboxen-based fibers, J.
Chromatogr. 873 (2000) 79-94.

[53] D.F. Steenson, J.H. Lee, D.B. Min, Solid phase microextraction of volatile soybean and corn oil compounds, J. Food. Sci. 67 (1) (2002) 71-76.

[54] D. Mateus, I.M.P.L.V.O. Ferreira, O. Pinho, Headspace SPME-GC/MS evaluation of ethanol retention in cooked meals containing alcoholic drinks, Food Chem. 126 (3) (2011) 1387-1392. 